\section{Letrônica}

\title{
Charqueadas e Xarqueada: a vida saladeiril na província gaúcha
}

1 Professora da Faculdade de Letras da PUCRS. Tem Mestrado e Doutorado em Linguística e Letras (Teoria Literária) pela PUCRS. Coordena o Curso de Especialização em Literatura Brasileira, da Faculdade
de Letras da PUCRS. É editora das revistas de Letras da PUCRS. É editora das revistas Letras de Hoje e Navegaçōes e membro do Centro de Literaturas de Expressăo Porde Lisboa.

E-mail:mariaeunice@pucrs.br
RESUMO: Análise do romance Xarqueada, de Pedro Wayne, apontando para a inovação da obra em relação ao Regionalismo literário sulino, como crítica às condições de produção do homem rural.

PalaVRAS-CHAVE: Regionalismo; Charqueada; Rio Grande do Sul.

ABSTRACT: Analysis of Xarqueada, a Pedro Wayne's novel, this narrative presents a description of the rural life's conditions in a "charqueada" in Rio Grande do Sul.

KEYworDS: Regionalism; “Charqueada”; Rio Grande do Sul. 
$\mathrm{N}$

início do século XIX, o botânico francês Auguste Prouvansal de Saint-Hilaire percorreu o interior do Brasil, durante seis anos, viajando das nascentes do rio São Francisco até a Província Cisplatina do Uruguai, no Extremo da Banda Oriental, percorrendo 2500 léguas no lombo de burro. Ás margens do rio Uruguai, foi envenenado pelo mel da abelha lechiguana, infortúnio do qual resultou longa e cruel e doença, e o atraso do relato de sua expedição às terras do Rio Grande. Viagem ao Rio Grande do Sul, último dos livros que escreveria ao retornar à Europa, constitui uma das mais fascinantes narrativas sobre os primórdios do continente sulino. Escrito em forma de diário, nele estão registrados dados estatísticos sobre a economia da região, hábitos e costumes do povo, e as anotações pessoais do viajante estrangeiro sobre uma terra que o assombrara pela vastidão e pela planura dos campos.

No dia 11 de setembro de 1820, o viajante estrangeiro estava hospedado na casa do Sr. Gonçalves Chaves, um abastado estancieiro da cidade de Pelotas e, segundo a informação de que dispunha, "um dos charqueadores mais humanos" (SAINT-HILAIRE, 1997, p. 86) da Província. Saint-Hilaire (1997), no entanto, observa que o estancieiro trata os escravos com muita severidade, especialmente um negrinho de dez a doze anos, que permanece sempre de pé, pronto a chamar alguém ou oferecer os seus préstimos à família. Esse menino "não se assenta, nunca sorri, jamais se diverte, passa vida tristemente apoiado à parede e é frequentemente, martirizado pelos filhos do patrão" (SAINT-HILAIRE, 1997, p. 87). O fato causa estranheza ao visitante, porque contradiz não só a opinião de que esse charqueador dispensa atenção a seus escravos, como se opõe à imagem de que os cativos são tratados com brandura, nessa parte do Brasil. Saint-Hilaire ouvira falar que, no Rio Grande, os brancos se familiarizam com os escravos muito mais do que noutros lugares, e que os proprietários tratam os cativos com amabilidade e até mesmo dispensam intimidade aos seus empregados. Essa amenidade no trato dos subalternos, do qual o pobre negrinho da casa seria uma exceção, torna-se contraditória na continuidade do diário, mostrando, novamente, que a exceção acaba por confirmar a regra. Se brancos e negros, patrões e escravos convivem familiarmente, diz ele que "isto é verdadeiro para os escravos das estâncias, que são poucos mas não o é para o das charqueadas que, sendo em grande número e cheios de vícios trazidos da capital, devem ser tratados com mais rigor" (SAINT-HILAIRE, 1997, p. 87). Eliminadas, portanto, as exceções, a prática de maltratar os escravos constitui uma das regras do comportamento dos gaúchos, quer trabalhem eles no interior das residências, como mandaletes, quer exerçam suas atividades como saladeiros, nas charqueadas, lugar onde o gado era abatido e a carne, salgada.

Nos anos seguintes à visita do naturalista francês, o Rio Grande foi agitado por uma longa e sangrenta luta - a Revolução Farroupilha ou Guerra do Farrapos, como também ficou conhecida - envolvendo partidários do Governo Imperial e os rio-grandenses contrários à política econômica do Império, sobretudo aquela que incidia sobre o charque e os produtos primários, especialmente o sal, necessário para a exploração dessa economia. Quando a revolta civil que abalou a Província por dez anos acabou, dela emergiu um novo homem e uma nova sociedade, que a História, em consórcio com a literatura, modelou e definiu, dentro de uma auréola de positividade. Terminada a guerra, nascia o gaúcho, herói forjado nos campos de batalha, homem forte, valente, destemido e audaz, cujos valores maiores - a liberdade e a lealdade - advêm das contendas. A mistura entre o homem do campo, porquanto durante a paz exercia atividades de força, como pelear e domar o gado, e de guerra, pois nas batalhas tornava-se exímio soldado e guerreiro, culminaram por definir um tipo - o gaúcho - pleno de virtudes. Trabalhando ao lado do patrão ou lutando com os estancieiros, transformados na guerra em generais e comandantes, essa situação construiu 
uma comunidade de homens socialmente equiparados, assentada na ideia de que a prática de tarefas comuns igualava seus praticantes. Daí nasceu a democracia campesina, mito no qual se fundou a sociedade rio-grandense no período pós-revolucionário. Os ventos do Republicanismo que sopraram nas planícies gaúchas acabaram por consolidar o tipo heróico do gaúcho e uma sociedade sem privilégios, mitificando o gaúcho pobre em herói regional e as relações desiguais entre patrão e empregado numa associação democrática e igualitária.

A exploração do regional, a promoção dos heróis nacionais e a exaltação dos valores próprios da cultura local, preconizados pelos românticos, junto aos anseios políticos dos rio-grandenses, e a combinação entre política e literatura foi responsável pela permanência e manutenção dos valores regionais, enquanto esteve no poder a oligarquia de orientação republicana que dominou a política no Rio Grande. A literatura, portanto, consagrou o mito, movimentando suas narrativas e seus heróis em páginas em que avultam a heroicidade e a vida igualitária. Mesmo a escravidão, que ainda na década de setenta do século dezenove poderia "denegrir" essa imagem, foi tratada por historiadores e literatos como um mal a ser extirpado e o Partido Republicano transformou a abolição em uma de suas batalhas mais vigorosas. Ser republicano e abolicionista, no plano político, correspondia, no plano literário, à adoção dos ideais românticos e à exploração da região no fazer literário. Daí nasce o Regionalismo gaúcho, marca da vida social e expressão da literatura, ideologia que, até hoje, aglutina gaúchos de diferentes procedências e responde ao imaginário de nacionais e estrangeiros sobre o Estado meridional.

Contudo, se a literatura delineou o tipo e a sociedade, no momento de constituição do Estado, que corresponde à de ascensão do Partido Republicano, embasado nas ideias de Comte e Spenser, encobriu, por outro lado, as mazelas que essa mesma sociedade registrava: o depauperamento do homem do campo, a perda do poder econômico das charqueadas e a falência de um modelo social, baseado no mito. O momento corresponde historicamente à década de trinta, do século vinte, quando ocorrem as modificações que alteram as bases ideológicas do poder, com repercussões profundas na literatura, sobretudo aquela que se constituiu sobre o eixo da exploração regional. Associados às transformações por que passam a vida e a literatura brasileira, os rumos da literatura regionalista precisam ser avaliados dentro do novo contexto histórico e ideológico. O Estado Novo que emerge, com os novos ares da industrialização, se não representa a almejada perspectiva ideológica progressista, proporciona a arregimentação das massa urbanas, emergentes face ao novo processo de industrialização. o Governo Federal favoreceu a camada burguesa, acelerou a marcha do operariado em busca de leis previdenciárias e trabalhistas, mas não mudou a estrutura agrária do País, permanecendo a cisão social entre campo e cidade.

No Rio Grande do Sul, o momento coincide com o fim do governo de Borges de Medeiros, que permanecera no poder ao longo de quase vinte e cinco anos, encerrando a dinastia de Júlio de Castilhos, responsável pela manutenção no poder da oligarquia pastoril. Encerrada essa fase da vida política, da qual o Regionalismo literário foi sua expressão na literatura, restava à literatura regional a alternativa de manter a sustentação de um passado cada vez mais mitificado, devido ao desaparecimento das condições que o engendraram, ou associar-se às novas tendências políticas e estéticas, $\mathrm{e}$ explorar as transformações de vida no Rio Grande como meio de sobreviver, enquanto assunto literário. A partir da década de 1930, acompanhando a evolução do romance brasileiro, a literatura rio-grandense assume um caráter documental, gerando obras de contundente crítica social, enfocando especialmente a região da Campanha, berço do regionalismo. Recuperamse elementos característicos do Regionalismo, mas despem-no de sua visão ufanista, substituindo a tendência festiva pelo desvelamento das desigualdades sociais. 
Coube ao baiano Pedro Rubens de Freitas Wayne tematizar as mazelas vividas pela classe de operários saladeiris, num dos estabelecimentos econômicos mais representativos da vida pastoril gaúcha, cem anos depois das anotações do viajante Saint-Hilaire. Wayne nasceu em Salvador, em 1904, mas ainda pequeno, com dois anos, foi morar em Pelotas, cidade onde permaneceu até 1927, quando se mudou para Bagé, como funcionário do antigo Banco Pelotense, constituído com capital dos pecuaristas gaúchos e liquidado em 1929. Jovem ainda, pegou em armas em 1930, na arrancada de Vargas, conspirou na revolução de 1932 e, para escapar da prisão, foi trabalhar como guarda-livros na charqueada de seu sogro, onde atendia o bolicho que supria os empregados do "saladero". Mais tarde, transferiuse para outra charqueada, até retornar a Bagé e participar do movimento artístico modernista, que reuniu nessa cidade da Campanha artistas plásticos como Glauco Rodrigues, Danúbio Gonçalves, de projeção regional, e Carlos Scliar, que alcançaria nome nacional.

Em 1937, depois de algumas experiências com versos, encaminhados para publicação pela Revista do Globo, em Porto Alegre, e publicados em espanhol, no Uruguai, Wayne passa a se dedicar à escrita de contos, romances, peças de teatro, e publica seu primeiro romance, Xarqueada. Editado pela Guanabara, do Rio de Janeiro, sob o patrocínio da Sociedade Felippe de Oliveira, com sede na Capital Federal, ${ }^{1}$ o livro aparece entre fins

\footnotetext{
${ }^{1}$ A Sociedade Literária Felippe de Oliveira foi criada em 23 de agosto de 1933, no Rio de Janeiro, em homenagem ao poeta santa-mariense, morto em acidente de carro, em Paris, nesse mesmo ano. A agremiação tinha por finalidade publicar as obras inéditas do poeta, reeditar outras, cultuar sua memória e divulgar escritores novos. Ao longo dos dez anos de existência, a Sociedade publicou um boletim, Lanterna Verde, e instituiu o Prêmio Felippe de Oliveira, concedido a escritores e poetas. Em 20 de março de 1936, foi instalado o núcleo português da Sociedade e destinado um prêmio anual, no valor de cinco mil escudos, para o melhor livro publicado em Portugal. V. WAYNE, Ernesto. Pedro pioneiro, o poeta peão. In: WAYNE Pedro. Xarqueada. Porto Alegre: IEL, Movimento, 1982 p. 12 (2 ed, 0 texto in poeta peáo. In: WAYNe, Pedro. Xarqueada. Porto Alegre: IEL, Movimento, 1982, p. 12 (2. ed.). O texto

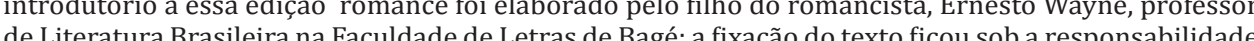
de Caros Jorge Appel, também professor de Literatura Brasile dra, ex Porto Alegre, e propriério da Editora Movimento.
}

de março ou início do mês de abril, o que se depreende do telegrama enviado ao autor, datado de 27 de março: "Xarqueada será exposto sábado todas livrarias cordialmente Sociedade Felippe de Oliveira" (WAYNE, Xarqueada, p. 12). 0 lançamento, contudo, estava previsto para o mês de fevereiro, segundo anúncio estampado no Diário da tarde, de Florianóplois, em $1^{\circ}$ de fevereiro de 1937:

\section{Aguardem}

Nos dias de fevereiro

XARQUEADA

Romance de Pedro Wayne

Com esse livro Pedro Wayne faz pelo Rio Grande do Sul o que Jorge Amado, José Lins do Rêgo, José Américo de Almeida fizeram e estão fazendo pelos Estados do Norte. E isto é para mostrar ao Brasil a verdadeira vida que se desenrola pelo seu interior. E é muito mais patriótico o que eles estão fazendo, do que entoar loas e cantar farturas e riquezas que não existem senão nas propagandas capciosas dos interessados em esconder ao País sua verdadeira situação. Edição da Editora Guanabara - Rua do Ouvidor, 132 - Rio de Janeiro (WAYNE, Xarqueada, p. 13).

Em maio de 1937, a revista Boa Nova, do Rio de Janeiro, divulga o romance, com o seguinte anúncio:

Em todas as livrarias, XARQUEADA por Pedro Wayne. Aspectos desconhecidos da vida no Brasil. Um romance numa reportagem. Um livro de estréia que é um sucesso magnífico. 0 autor esteve empregado como "peão" em uma xarqueada [sic] para estudar ao vivo o ambiente do seu romance. Pedidos à Empresa Graphica BOA NOVA (WAYNE, Xarqueada, p. 12-13)

$\mathrm{O}$ apelo ao inusitado, ao original, que a região sulina pode oferecer à nova narrativa brasileira parece realmente consistir na tônica dominante da divulgação do romance de Pedro Wayne, razão pela qual os exemplares da primeira edição vinham cingidos por uma faixa amarela, onde estava escrito: Aspectos desconhecidos da vida no Brasil. A revelação de um escritor cuja estréia a Sociedade Felippe de Oliveira tem prazer em patrocinar. Além 
do patrocínio, o livro apresentava-se de certa forma paraninfado por dois escritores nacionais: um era Erico Verissimo; o outro, Jorge Amado. A eles, Wayne havia dedicado Xarqueada e, em carta sem data datilografada por Erico Verissimo e complementada a mão por Jorge Amado, recebeu o autor as seguintes palavras:

Recebi a sua carta e fiquei muito satisfeito por saber que o seu romance encontrou um editor - e editor de primeira ordem. (...)

Jorge Amado acha-se em Porto Alegre desde terça-feira passada. Vai a Buenos Aires, de onde viajará para o Chile, ponto de partida de uma longa viagem pela costa do Pacífico até México e naturalmente Estados Unidos.

E nós sempre parados, seu Wayne!

Não há de ser nada.

Um abraço do

(a) Erico Verissimo

Jorge Amado, a quem coube o post-scriptum, escreveu em tinta verde:

Wayne: Parabéns pela saída do teu romance. Tou aqui de passagem. Mande o meu exemplar pro Erico, que fará chegar às minhas mãos. Pro Prêmio, envie

5 para F. Graça Aranha - Praia do Flamengo, 116 - 8o andar e também para

D. Nazareth Prado, mesmo endereço. (a) Jorge Amado

Mas afinal, de que trata esse romance tão anunciado, esperado e paraninfado? Em que ele se opõe ao modelo regionalista da ficção sul-riograndense? A que responde o autor quando coloca em cena a charqueada, seus contornos e seus protagonistas?

Xarqueada (grafado com x por sugestão de Jorge Amado, que achava que "o público gosta de título pequeno"2), enfoca a vida numa charqueada,

\footnotetext{
${ }^{2}$ Quando passava o Carnaval de 1935, no Rio de Janeiro, Jorge Amado recebeu uma carta de Pedro Wayne, por intermédio de Oswald de Andrade, que a repassara ao escritor baiano por acreditar que esse tinha mais familiaridades com questões de edič̃o. Na resposta enviada a Wayne Jorge Amar que . us pioneiro, o poeta peão. In: WAYNE, Pedro. Xarqueada. Porto Alegre: IEL, Movimento, 1982. p. 17.
}

no interior do Rio Grande do Sul, colocando em cena todos os protagonistas do universo saladeiril: o estancieiro, proprietário do estabelecimento, o capataz, chefe dos empregados, e os diferentes trabalhadores: matadores, salgadores, aguadeiros, bolicheiros, nas suas diferentes relações de poder e de afeto. Dionísio, o patrão, casado com Vera, uma mulher fútil e malvada, que se juntara a ele por interesses, toma por amante Daniela, mulher de um tuberculoso, empregado na charqueada, que se prostitui em troca de favores ao marido. A chegada de Luís, o novo guarda-livros, transforma o ambiente rural, pois o rapaz não só incita os trabalhadores à luta por seus direitos, o que culmina com uma greve na estância, como também inicia um relacionamento sério com Guriazinha, uma jovem desconsiderada pelos demais, por ter sido desvirginada pelo antigo namorado. Se o tema central do romance gira em torno da experiência do guarda-livros que se torna líder dos trabalhadores saladeiris, o romance envolve um contingente de personagens e situações típicas de seus fazeres, permitindo uma observação dos processos dinâmicos do mundo rural rio-grandense, tomando como ponto privilegiado de observação o espaço da charqueada, base da economia gaúcha. É, portanto, nesse espaço - misto de família e indústria - que aparecem os conflitos de uma sociedade que se preparava para o progresso e que visava ao capital.

O ponto de partida para a análise do romance é o espaço tematizado pelo narrador, que funciona como lugar das relações econômicas e dos conflitos de caráter interpessoal. A charqueada, na década de trinta, no momento de implantação da sociedade industrial, significava, especialmente para o patrão, a indústria moderna, em oposição aos mecanismos tradicionais da vida rural, oferecendo condições excepcionais de trabalho a seus empregados, conforme registra Sandra Pesavento, em A burguesia gaúcha:

As fábricas eram descritas como modernas e higiênicas, e o trabalho que se desenvolvia nas diferentes secções era harmônico, num ambiente cordial. Os 
operários, por seu lado, eram referidos como robustos, sadios e ordeiros. Em suma, um perfeito reduto de 'ordem e progresso' sob a batuta de dinâmicos e clarividentes capitães de indústria... (PESAVENTO, 1988. p. 31).

No campo, a transformação podia ser observada nos seus pequenos detalhes: o trabalho rural, antes praticado ao ar livre, passava a ser desenvolvido em espaço fechado; o tempo, regulado pelo sol e pelas mudanças climáticas, vinha marcado pelo apito da caldeira e pela ideia de jornada; o pagamento, antes variável, torna-se estável e tem valor diário, transformando o peão sem soldo em empregado assalariado. $O$ quadro delineado sugeria, portanto, uma alteração nas condições de trabalho dos empregados, não apenas no que diz respeito à ordem trabalhista, mas também em relação ao próprio ambiente de trabalho.

Xarqueada, o romance, constrói-se exatamente na negação do paradigma de industrialização, a partir de sua página de abertura. Nela, a situação registrada pelo narrador não corresponde ao modelo de limpeza e asseio, reconhecido como destaque na indústria gaúcha. Ao contrário, desde os primeiros parágrafos ficam evidentes as condições de desolação e insalubridade do estabelecimento:

Luís nunca tinha entrado numa xarqueada. Sabia apenas que era um lugar onde os passageiros dos trens baixavam apressadamente as janelas por causa do fétido insuportável. Parecia que havia no ar, dissolvidas em amoníaco, todas as catingas que existem, tão penetrantes e nauseabundas emanações exalavam. Vira também pela vidraça do comboio uns compridos prédios de material, cobertos de zinco, tendo um pouco adiante das construções, longas filas feitas de paus em forma de golos baixos, onde às vezes grupos de homens descalços, ensebados, estendiam grandes pedaços de xarque, que traziam em carrinhos de mão. Depois soube que eram ali os "varais". E que o mau cheiro vinha de ossos podres à espera de serem vendidos para as fábricas de adubos (WAYNE, 1982. p. 19).

O odor pútrido, que exalava desses lugares, descrito por diferentes viajantes como "cheiro de carniça" ou "cheiro de açougue", era totalmente negligenciado pelos proprietários, pelo menos por dois motivos: em primeiro lugar, porque a instalação de equipamentos mais adequados representava investimento de capital, o que não valia a pena, principalmente porque muitos estancieiros já se encontravam endividados; em segundo, o perfil retrógrado da maioria dos charqueadores, contrários aos recursos de modernização que já se anunciavam na nascente indústria gaúcha, impedia a tomada de medidas inovadoras e condizentes com os novos tempos.

A organização do trabalho, exaltada como forma de obter maior rendimento da produtividade, não é também reconhecida no relato de Pedro Wayne. Antes de começar a jornada de trabalho, azeitavam-se as máquinas, inspecionava-se o nível de sal dos tanques, taravam-se as balanças, revisavase a instalação elétrica, para o serviço noturno e afiavam-se as facas de dois gumes, colocando-as ao alcance da mão, para o rápido abate da rês. 0 trabalho parece organizar-se, observando uma certa ordem, em que cada empregado, colocado no seu devido lugar, transforma-se numa peça na engrenagem da "moderna" charqueada, como uma linha de montagem das fábricas robotizadas atuais.

Os preparativos agitavam braços e vaivém de homens.

Carrinhos salgados de sal se derramavam no monte farto e branco que clareava alto num canto da salga pronto para ser lequeado pelas pás ágeis dos salgadores. (...) Os tanques limpos, cheiros de salmoura, borbulhavam bem dosados. (...) Azeitava-se zelosamente o guincho a vapor que arrastava os animais amedrontados para o sacrifício. Taravam as balanças. (...) As facas de dois gumes, com que desnucavam as reses, sobre a parede alta da mangueira, ao alcance da mão do desnucador. A instalação elétrica, revisada (...) 0 nível da água, cuidado (WAYNE, 1982, p. 35-36)

No entanto, se a descrição do romance reafirma a especialidade de cada homem, contradiz, contudo, com o cansaço da jornada, o meio enlameado e molhado do galpão, a falta de comida e a dureza das atividades ali praticadas: 
O serviço puxado, exigindo muita força muscular, cansava aqueles homens em jejum. 0 chão coberto d'água, que lhes tapava os pés, as vestes molhadas sobre a pele, amolecia-os o vigor (...) Esfalfados. Até apitar o café, não lhes davam tréguas nem autorização para se alimentarem. (...) 0 machadeiro no contínuo levantar e baixar o machado sobre os esqueletos para parti-los (...) Os salgadores já não tinham a mesma habilidade ao manejar as pás (...) Os ganchadores, enfraquecendo (...) Os que trabalhavam, dobrados sobre os rins, com as cinturas como se estivessem rachadas de tanto que doíam (WAYNE, 1982, p. 47-48)

Uma das características do regime de trabalho na charqueada era a longa duração da jornada. Desde a hora em que começava a matança de gado, os empregados não podiam parar, a não ser por breves minutos para tomar água. A obrigação de trabalhar decorria da necessidade de obter maior salário, quanto também de uma lei vigente entre os homens, que considerava fraco aquele que não aguentasse a jornada. Eles "tinham que aguentar no duro, não só porque eram aqueles os dias com que contavam para ganhar uns cobrezinhos, (...), como também para conservar o nome de bom peão. 0 que fracassasse e se deixasse vencer pelo cansaço era considerado 'molóide'” (WAYNE, 1982, p. 62), e teria problemas para obter colocação em outro estabelecimento.

A necessidade de suportar a jornada, sem atendimento das necessidades mínimas de descanso e alimentação, era ainda agravada pelo iminente perigo em que viviam os homens, em contato direto com equipamentos obsoletos, sob os quais não havia fiscalização. Para os charqueadores, as exigências de segurança não consistia nenhuma prioridade. Mais do que uma negligência administrativa, o fato revelava também o desconhecimento da necessidade de assistência técnica e o baixo investimento na charqueada gaúcha. O Governo Estado, a quem interessava a modernização dos estabelecimentos pecuários e a maior exploração dos negócios do campo, tampouco apresentava políticas eficientes para incrementar o setor, que não dispunha sequer de fiscalização veterinária.
A precariedade das condições de trabalho estendia-se à remuneração oferecida ao trabalhador: pelo mesmo serviço, um homem podia ganhar mais do que o outro, chegando a um deságio de $50 \%$ entre o mais alto e o mais baixo salário. Desse modo, atividades idênticas eram cotadas de forma diferentes, definida pelas arbitrariedades do patrão que determinava os salários a serem atribuídos a cada empregado. A medida podia ter outra justificativa: além de ser um meio aparente para incentivar a produção, a política de diferenciação salarial visava também regular o crédito do empregado junto ao bolicho. 0 bolicho era o lugar das compras, "financiadas" pelo charqueador, também dono desse pequeno armazém, de modo que o lucro da venda era igualmente obtida pelo patrão. Assim, o salário que o empregado deveria receber ao final da safra estava comprometido com as compras antecipadas, praticamente nada sobrando para enfrentar a entressafra, temporada na qual os homens se dedicavam a atividades esporádicas e eventuais

Rompe-se, aqui, a concepção de que o capital era obtido como obra comum dos homens, tendo, portanto, uma natureza social, como ressaltava a ficção regionalista, ao explorar a democracia campesina. Na verdade, o regime trabalhista vigente na charqueada é o da exploração do trabalho coletivo e a apropriação dos lucros do capital favorece apenas o capitalista, ou seja, o charqueador. Nesse caso, o republicanismo de base positivista que grassou no Rio Grande, do início do século vinte até a década de trinta, através da filosofia castilhista, oferecia as bases ideológicas para a submissão do mais fraco ao mais forte. Segundo a proposta positivista, há uma clara distinção entre os que detêm o saber técnico-científico e estão aptos a comandar e o restante da sociedade, a quem compete obedecer, conforme os moldes da sociedade hierarquizada preconizada por Spencer, teórico lido e frequentemente citado pela elite intelectual gaúcha.

A greve, que ocorre ao final da narrativa, não reverte a situação de exploração vivida pelo homem do campo. Mesmo os olhares de desagrado, 
as observações críticas e o incitamento à rebelião, provocados por Luís, o guarda-livros que se rebela contra a situação vivida pela gente da campanha, não resulta na modificação desse status quo. Apesar das ameaças do patrão de que a turma de grevistas seria substituída por uma equipe contratada em outras fazendas, a greve culmina com o retorno dos empregados ao trabalho, sem que qualquer vantagem tivesse sido obtida. A promessa do estancieiro resumia-se então na recolocação de todos, com a o observação de que não aumentaria os ordenados. Mais uma vez, a política de base positivista, que recomenda a ordem a favor do progresso, soma ponto na decisão final, respondendo, aparentemente, aos interesses dos trabalhadores - não perder o emprego - embora fosse claro o alinhamento da classe dirigente - o charqueador - ao lado do capital. A solução preconizada ajusta-se, portanto, aos interesses da ótica capitalista, deixando para mais tarde a proposição de medidas revolucionárias ou de caráter social mais consistente.

Resta, então, ao narrador, encerrar o romance sob o signo do amor, aproximando Luís de Guriazinha, o que recoloca a menina no círculo social, pela instituição de sua união com um homem de um círculo mais culto e estranho ao da charqueada. Nesse caso, Wayne reforça a moral vigente na sociedade burguesa, promovendo o casamento como um meio de solucionar os problemas da honra e reequilibrar a ordem social. Aliás, a ideia de justiça social que emerge do romance apoia-se muito mais no amor como forma de solução para os problemas, amor esse que supera o da relação entre um homem e uma mulher para se manifestar como a fraternidade entre os homens, a solidariedade entre os amigos e a cumplicidade entre as mulheres. O desamor, seu oposto, está presente nas relações desajustadas, sejam elas a do patrão e sua mulher interesseira, a do amigo que trai a confiança do outro ou a do próprio Estado, indiferente a uma política capaz de promover a verdadeira e justa revolução social.
É nessa medida que o romance Xarqueada revela sua inovação em relação à literatura regionalista, não só porque formula a crítica e a denúncia de um período da história do Rio Grande do Sul, mas também porque seu autor situa-se na contramão do Regionalismo ufanista e idealista que marcou a produção ficcional do Estado. Sob sua ótica, focaliza a realidade das condições de produção do homem rural, problematizando o real em seus diferentes níveis, do social ao individual, do mítico ao histórico.

Nesse sentido, Pedro Wayne não estava tão parado, como supunha Erico Verissimo, mas, com sua narrativa, colocava o dedo justamente sobre uma ferida da história: a da instituição na qual se sustentou a economia gaúcha e do regime capitalista que imperou nas relações entre patrão em empregados, durante a República Velha. As misérias que o romance descobre não dizem respeito apenas a um possível atendimento da necessidade pessoal do escritor Pedro Wayne de promover sua catarse, ao escrever Xarqueada, mas vai mais longe ao sugerir que as linhas traçadas são detalhes de um sombrio painel histórico, muito mais amplo do que a vastidão dos campos que fascinou o viajante francês Saint-Hilaire, naquele distante e, muitas vezes, esquecido início do século dezenove, na Província mais meridional do continente brasileiro.

\section{Referências}

PESAVENTO, Sandra Jatahy. A burguesia gaúcha: dominação do capital e disciplina do trabalho. (RS: 1889-1930). Porto Alegre: Mercado Aberto, 1988.

WAYNE, Pedro. Xarqueada. Porto Alegre: IEL/Movimento, 1982.

SAINT-HILAIRE, Auguste. Viagem ao Rio Grande do Sul. Porto Alegre: Martins Livreiro, 1997.

Recebido em 20/01/2016 Aprovado em 01/05/2016 